\title{
Knowledge of nursing students towards HIV/AIDS in Nepal
}

\section{Sita Parajulee, ${ }^{1}$ Valarmathi Selvaraj ${ }^{2}$}

${ }^{1}$ Assistant Professor and Program Chief of Nursing program, ${ }^{2}$ Lecturer, Nursing program College of Medical Sciences, Bharatpur, Nepal

\section{Abstract}

\section{Aims}

First case of Acquired Immuno Deficiency Syndrome (AIDS) in Nepal was reported in the year 1988. Nurses are an integral part of the healthcare system and should be knowledgeable in providing care to AIDS patients. This study assessed the knowledge of nursing students towards HIV/AIDS, and the association (if any) between the knowledge scores of the nursing students with their selected demographic variables.

\section{Materials and methods}

A cross sectional study was conducted evaluating the nursing student knowledge using a self designed questionnaire. The correct answers were given a score of ' 1 ' and wrong answers were given a score of ' 0 ' (total possible maximum score ' 18 ').

\section{Results}

Among the total 165 nursing students, 121 of them filled the questionnaire (response rate of 73.33\%) and all of them were females. The mean \pm SD age of the respondents was $18.3 \pm 1.75$ years. The median (IQR) of the overall total scores was 13.0 (11.5-15.0). There was an association between the knowledge scores of the respondents with 'age' $(p=000)$, 'course of the study' $(p=0.001)$. However, there was no statistically significant association between the knowledge scores with the 'year of study' of the respondents ( $p=0.109)$, 'mode of finance' $(0.611)$ and 'native' of the students $(0.173)$.

\section{Conclusion}

The study suggested that nursing students have a poor overall knowledge on AIDS and especially areas such as post exposure prophylaxis.The findings also suggested the need for providing adequate knowledge to the students during their regular class room teaching and clinical postings.

\section{Key words: Knowledge, nursing students, HIV/AIDS, Nepal.}

Correspondence: Ms. Valarmathi Selvaraj

Email:valarmathisubish@gmail.com 


\section{Introduction}

AIDS is as an infectious disease caused by the human immunodeficiency virus (HIV). There are two variants of the HIV virus, HIV-1 and HIV-2, both of which ultimately cause AIDS. ${ }^{1}$ AIDS is referred to as a syndrome because the range of manifestations may include a variety of opportunistic infections, neurological disorders and malignancies. The evidence on the first case of AIDS in Nepal was reported in the year 1988. By the middle of the year 2008 there were more than 1,750 cases of AIDS and more than 11,000 cases of HIV infection were officially reported. It was reported that men were affected two times more than that of women. The UNAIDS estimated that 70,000 people were living with HIV at the end of the year $2007 .^{2}$

Nurses are an integral part of the healthcare system and are perceived to be knowledgeable in providing institutional and community health care to the patients. They play an important role in providing healthcare to patients, especially in rural areas of Nepal as there are less number of doctors. The role of nurses is even becomes more critical in a society that is battling to control and prevent HIV/ AIDS infection and related superinfections. Nurses are usually at the forefront of patient care. So when they are as students they need to have an adequate knowledge and a positive attitude towards healthcare problems including HIV/AIDS which has recently become a major public health concern in the country. In contrary to their roles, studies from different countries have reported a poor knowledge among the nurses regarding HIV/AIDS. 3,4,5 Identifying the knowledge of nursing students may provide baseline data which may then be a useful source for intervention.

In Nepal, the basic nursing programs, the Diploma and Bachelor programs in Nurses lay adequate emphasis on the HIV/AIDS. However, the retention of this knowledge among the nurses at the practitioner stage can be doubtful. Understanding thesenurses knowledge can help in planning for proper training and continuous nursing programs (CNE) for the practicing nurses. The data regarding the nurses' knowledge on HIV/AIDS are limited. During or literature review we could locate only one study related to this topic carried out in Nepal. In that study authors found Nepalese nursing students to have a large knowledge gap and negative attitudes, regardless of level of education. Astudy done at Kathmandu Valley by Mahat and Eller suggested that curricula must include adequate and culturally relevant content on HIV/AIDS, attitudes towards people living with AIDS, and universal precautions. ${ }^{6}$ As there are no studies from other parts of Nepal, this study was carried out to assess the knowledge of nursing students towards HIV/AIDS and to study the association between the knowledge scores of the nursing students with their selected demographic variables.

\section{Methodology}

Study design: A cross sectional study evaluating the knowledge of the nursing students regarding HIV/ AIDS.

Study site: College of Medical Sciences-Teaching Hospital (CMS-TH), a tertiary care teaching hospital that also runs a Bachelor of Science (BSc) and Proficiency Certificate Level (PCL) nursing programs.

Study subjects: The subjects were the nursing students from both BSc first year, second year and PCL first, second and third year. PCL program is three year course and BSc nursing program is four year course. Inclusion and exclusion criteria: All the nursing students are who were present during the study period 
Sita Parajulee et al. Knowledge of nursing students towards HIV/AIDS in Nepal.

were enrolled. The ones on leave were excluded from the study.

Study tools: A self designed questionnaire was used in the study. The questionnaire had 18 questions. This questionnaire was developed by the researchers in consultation with an expert in pharmacoepidemiology. The face and content validity was carried out through discussion among the researchers and the expert.

Method of data collection: The researchers personally went to the subjects and got the questionnaire filled by them. Adequate time (nearly 30 minutes) was given to each respondent for filling the questionnaire.

Data analysis: The filled questionnaires were collected and the data were entered in Microsoft Excel spreadsheet and were analyzed as per the study objectives. The correct answers were given a score of
' 1 ' and wrong answers were given a score of ' 0 '. Thus making the total possible score to be '18'.

Statistical analysis: The SPSS Version 16 was used to carry the statistical analysis. Mean and standard deviation were carried out for the demographic variables and Kruskal Wallis test was used to compare the mean scores with the respondents demographic variables.

\section{Results}

Demographic details of the respondents: Among the total 165 nursing students, 121 of them filled the questionnaire (response rate of 73.33\%) and all of them were females. A high percentage $(65.29 \% \mathrm{n}=70)$ of them belonged to the age group 18-20 years and the mean \pm sd age of the respondents was $18.3 \pm 1.75$ years. Further details regarding the demography of the respondents are mentioned in Table 1.

Table 1. Demographic distribution of the respondents $(n=121)$

$\begin{array}{lccc}\text { Parameters } & \text { Interval } & \text { Number } & \text { Percentage } \\ \text { Age (in years) } & \text { Less than } 18 & 38 & 31.40 \\ (\text { mean } \pm \text { sd }= & 18-20 & 79 & 65.29 \\ 18.3 \pm 1.75) & \text { More than } 20 & 4 & 3.31 \\ \text { Course } & \text { B.Sc N ursing } & 42 & 34.71 \\ & \text { PCL } & 79 & 65.29 \\ \text { Year of study } & 1 & 64 & 52.89 \\ & 2 & 28 & 23.14 \\ \text { Year } & 3 & 29 & 23.97 \\ & \text { B.Sc first year } & 22 & 18.18 \\ & \text { B.Sc second year } & 20 & 16.53 \\ \text { Financing } & \text { PCL first year } & 42 & 34.71 \\ & \text { PCL second year } & 5 & 4.13 \\ \text { Native } & \text { PCL third year } & 32 & 26.45 \\ & \text { Scholar } & 16 & 13.22 \\ & \text { Self } & 105 & 86.78 \\ & \text { Urban } & 13 & 10.74 \\ & \text { Rural } & 108 & 89.26\end{array}$


Comparison of respondents' total score with demography:

The median (IQR) of the overall total scores is 13.0 (11.5-15.0).

There was an association between the knowledge scores of the respondents with 'age' $(\mathrm{p}=000)$. Similarly there was also an association between the course of the study and the total scores $(\mathrm{p}=0.001)$. However, there was no statistically significant association between the knowledge scores with the 'year of study' of the respondents $(p=0.109)$, mode of finance (0.611) and native of the students (0.173). The details regarding the comparison of the respondents' total score with demography are listed in Table 2.

Table 2. Total scores of the respondents with demographic variables

$\begin{array}{llll}\text { Parameters } & \text { Interval } & \text { Median (IQR) scores } & \text { P Value } \\ \text { Age } & \text { Less than } 18 & 12(11-13.25) & \mathbf{0 . 0 0 0 *} \\ & 18-20 & 14(12-16) & \\ \text { More than20 } & 11.5(8.75-12.0) & 0.001 * * \\ \text { Course } & \text { BSc } & 13.5(12.7-16.0) & 0.109 * \\ \text { Year of study } & \text { PCL } & 12(11-15) & \\ & 1 & 13(11-14.75) & 0.611 * * \\ \text { Mode of financing } & 2 & 13(12-16) & \\ & 3 & 14(12-15) & 0.173 * * \\ \text { Native } & \text { Self } & 13(12-15) & \end{array}$

* Kruskal Wallis test ** Manwhitney U test

Note: Higher the score better is the knowledge

Responses of the nurses to individual statements:

It was found that all (100\%) the students knew the expansion of the term 'AIDS'. Similarly a high percentage (94.21\%, $n=114$ ) of the respondents knew the 'name of the virus which causes AIDS' and the 'modes of transmission of HIV virus'. It was also found that only less than one third $(28.93 \%, n=35)$ of the respondents knew the 'time taken by the patient to develop signs and symptoms appear after expose to HIV virus'. Further details on the knowledge responses by the respondents to individual questions are listed in Table 3. 
Sita Parajulee et al. Knowledge of nursing students towards HIV/AIDS in Nepal.

Table 3. Responses of the nurses to individual statements $(n=121)$

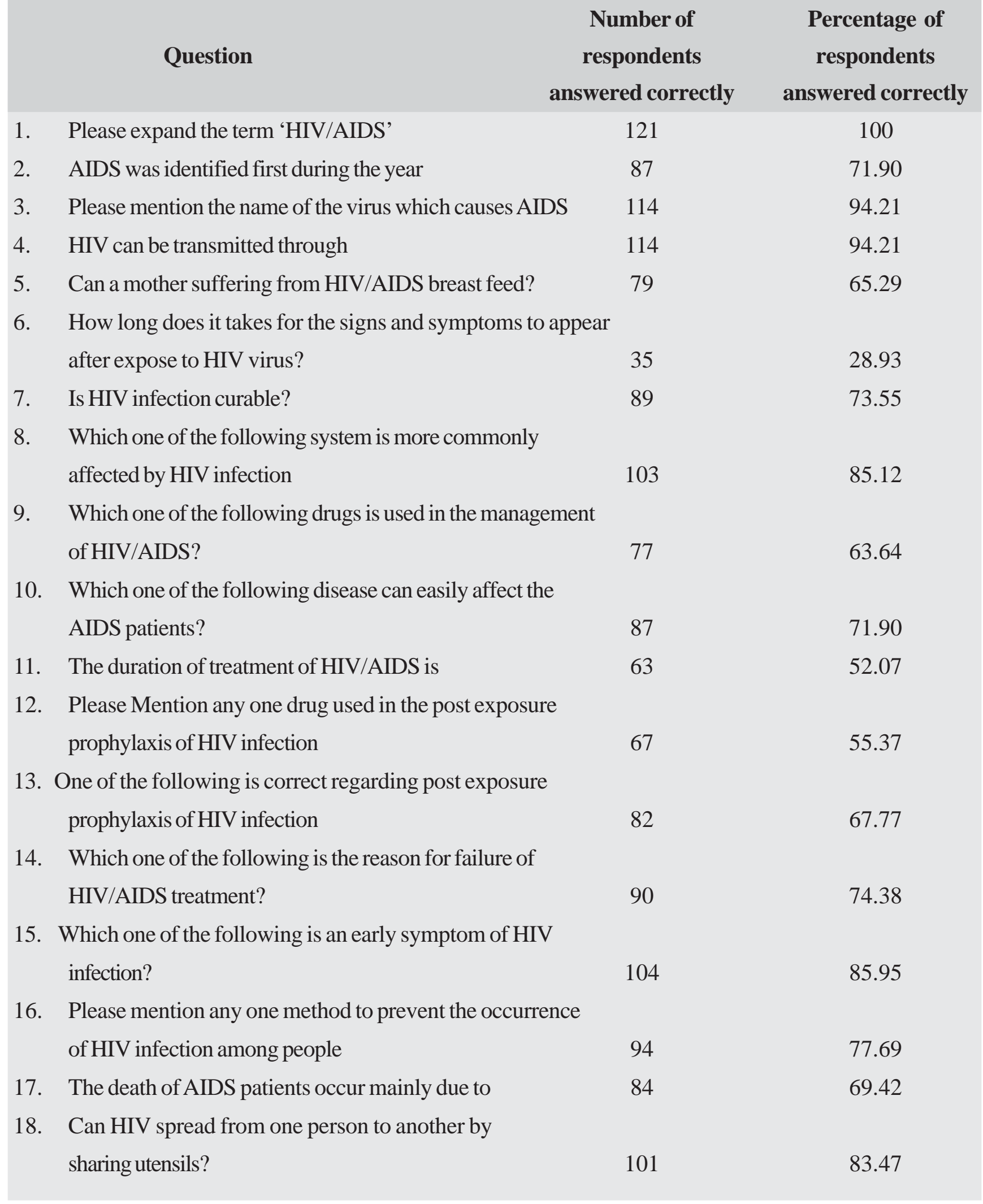

Note: Total number of respondents is 121 


\section{Discussion}

HIV/AIDS is becoming a major public health concern in Nepal. Nurses play an important role in battling this dreadful condition. Nurses can provide health education on prevention strategies to general public, having adequate knowledge help them in overcoming social stigma associated with HIV infection, and can provide better institutional care. In ordered to perform their roles the nurses need to be knowledgeable on HIV/ AIDS and related matters. It is also imperative for the nursing students to possess a good knowledge that would help them for a better practice while they become nursing practitioners.

In our study there were both B.Sc Nursing students and PCL nursing students. The overall scores were found to be high in case of B.Sc nursing students. The reason may be due to the fact that the BSc nursing students get admitted only after completing intermediate science(10+2) whereas the PCL nursing students get admission after completing class 10 .

In a study from Turkey 227 nursing students from the School of Health were studied during the year 2005/ 2006 which showed that the students who had previous experience in caring for an AIDS patient and had known someone with HIV/AIDS were willing to care for people having HIV. Hence the need to strengthen nursing education on all aspects of HIV/ AIDS. ${ }^{7}$

In our study nearly $75 \%$ of the respondents answered correctly for the question 'Is HIV infection curable?' Actually AIDS is not a curable disease and hence prevention strategies are the most important methods to overcome this problem. Normally HIV spreads through direct blood-blood contact and it is important for a nurse to know this since this may be a preventive factor for nurses to care for a HIV patient. Similarly, in case of accidental exposures the nurse should take adequate treatment and thus it is very much essential for the nurse to understand the mode of transmission of HIV virus. Similarly in our study only slightly more than half the number of respondents were aware of the drug used in post exposure prophylaxis.

\section{Conclusion}

The study suggests that nursing students have poor knowledge on AIDS/HIV and hence the need for providing adequate knowledge to the nursing students during their regular class room teaching.

\section{Acknowledgements}

Authors would like to acknowledge all the students who provided their responses by filling the knowledge questionnaire.

\section{References}

1. AIDS definition available at http://medicaldictionary.thefreedictionary.com/AIDS (Accessed April 2012)

2. HIV/AIDS in Nepal. World Bank Report, August 2008. Available at www.worldbank.org/saraids

3. A. Tavoosi, A. Zaferani, A. Enzavaei. Knowledge and attitude towards HIV/AIDS among Iranian students. Biomed Central Public Health. 2005; 4:17-22.

4. C. Lohrmann, M. Valikaki, T. Suominen et al. nursing students' knowledge of and attitudes to 
Sita Parajulee et al. Knowledge of nursing students towards HIV/AIDS in Nepal.

HIV and AIDS: two decades after the first AIDS cases. J Adv Nurs. 2000; 31 (3): 696-703.

5. H.A. Bektas, O. Kulakac. Knowledge and attitudes of nursing students toward patients living with HIV/AIDS (PLHIV): A Turkish perspective. AIDS Care. 2007; 19 (7):888-94.

6. G. Mahat , L.S. Eller . HIV/AIDS and universal precautions: knowledge and attitudes of
Nepalese nursing students. J Adv Nurs. 2009; 65(9):1907-15.

7. H.A. Bekta ${ }^{\circ}$, O.Kulakaç . Knowledge and attitudes of nursing students toward patients living with HIV/AIDS (PLHIV): a Turkish perspective. AIDS Care. 2007;19 (7):888-94 